\title{
Simplified mathematical model for analyzing the effects of urban heat island by using WRF and building thermal simulations
}

\author{
Ivan Oropeza-Perez \\ Department of Architecture, Universidad de las Americas Puebla, San Andres Cholula, Mexico \\ email: ivan.oropeza@udlap.mx
}

\begin{abstract}
In this document, the thermal performance of a heat island onto an urban area and it surrounding buildings is analyzed with weather research and forecasting (WRF) simulation modeling and the building thermal program EnergyPlus and then it is validated with literature. Different methods of shading and cooling, varying physical values such as thermal transmittance and absorption are applied in order to find the most influencing feature upon the temperature drop into a simulation loop. After a simplified mathematical model is developed that deals with the performance of various shading and cooling methods according to the physical, urban and climatic characteristics of the local place, the calculated results achieve a good agreement with the already-published results. With this, it is expected to have a reliable model that helps to understand the urban heat island effect in terms of the indoor thermal comfort of its surrounding buildings.
\end{abstract}

\section{Introduction}

The current situation in the world enforces new and better manners of dispatching energy for the every-day human activities. These manners should fulfill various characteristics that do not affect the environment like the increase of the so-called climate change, which is the most challenging issue faced by the human kind and whose origin is shared in a great extent by energy-related activities.

Furthermore, in a city context, the so-called urban heat island is a phenome that grows every time in amount and intensity along over the world. This phenome comprises the increase of the local air temperature, the indirect solar radiation and other physical characteristics that implies thermal discomfort upon the inhabitants. Other consequence of the heat island is the occurred onto the surrounding buildings, which are affected in their indoor environment, generally increasing the indoor temperature therefore enforcing the use of a cooling method such as fans and air-conditioning systems with the consequence of energy consumption ( $\mathrm{Li}$ et al., 2019).

Several authors have focused on the use of techniques to decrease the air temperature and the solar radiation by applying green infrastructure, reflective materials and natural ventilation, among other approaches (Morini et al., 2018; Yuan et al. 2016)
This document has the purpose of assessing the different techniques of shading and others that reduce the air temperature and the direct solar radiation, mainly, through a mathematical model that calculates the physical characteristics of the heat island. The first input data (global solar irradiance, dew point, temperature of sky and air temperature) are calculated with WRF simulation modeling. Then, the mathematical model determines the second input data with different approaches of heat island effect reduction. These data are used in EnergyPlus to calculate the indoor temperature and relative humidity and the thermal comfort by using the PMV index. Finally, the daily cooling demand is estimated.

\section{Methodology}

WRF modeling is a numerical analysis system that calculates the atmospheric features such as cloudiness, solar radiation, wind speed, wind direction, atmospheric pressure, relative humidity and outdoor temperature (Mesoscale and Microscale Meteorology Laboratory, 2019). In this document, some of these characteristics are taken as input data in a simplified mathematical model developed hereby to calculate an input dataset that is used in EnergyPlus (US Department of Energy, 2019) calculating thus the indoor thermal comfort conditions of the surrounding buildings. A diagram of the calculation method is shown in Figure 1.

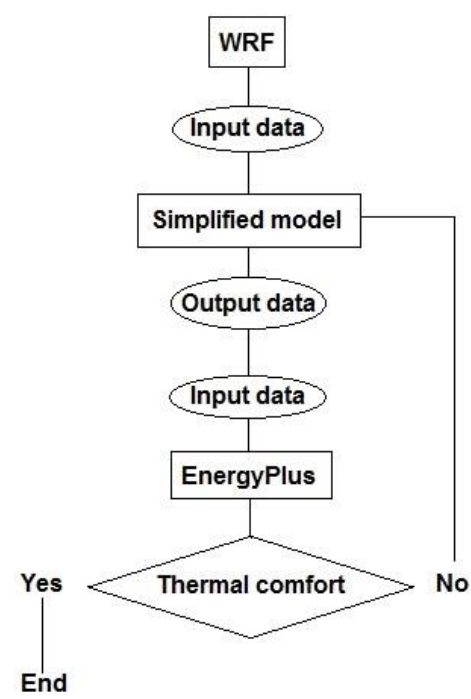

Figure 1: Calculation method of thermal comfort onto an urban heat island by using a simplified mathematical model. 
The WRF model has been used to simulate urban heat islands in previous documents in different parts of the world (Chen et al., 2014; Giannaros et al., 2018; Jandaghian et al., 2018; Li et al., 2019). Nevertheless, there is not, to our best of knowledge, a comprehensive workflow between WRF and a thermal building simulation modelling to analyze the impact of the urban heat island effect upon the air-conditioning consumption. On the other hand, there are measurements of airconditioning consumption within buildings taking account of the urban heat island. Nonetheless, these measurements were estimated based on actual meteorological data (Yang et al., 2019; Hirano and Fujita, 2016; Allegrini and Carmeliet, 2018). Therefore, in this document, a combination of both models is applied in order to estimate, in a simpler manner, reliable consumptions of air-conditioning upon buildings and carry out an assessment of the different strategies of reduction of the urban heat island effect.

\section{Urban heat island}

The phenomenon of urban heat island consists in "an urban area or metropolitan area that is significantly warmer than its surrounding rural areas due to human activities" (Mirzae, 2015). According to literature, the first cause of the temperature increase is the modification of land surfaces, followed by the waste heat from a certain energy activity. The main heat flows of the urban heat island can be seen in Figure 2.

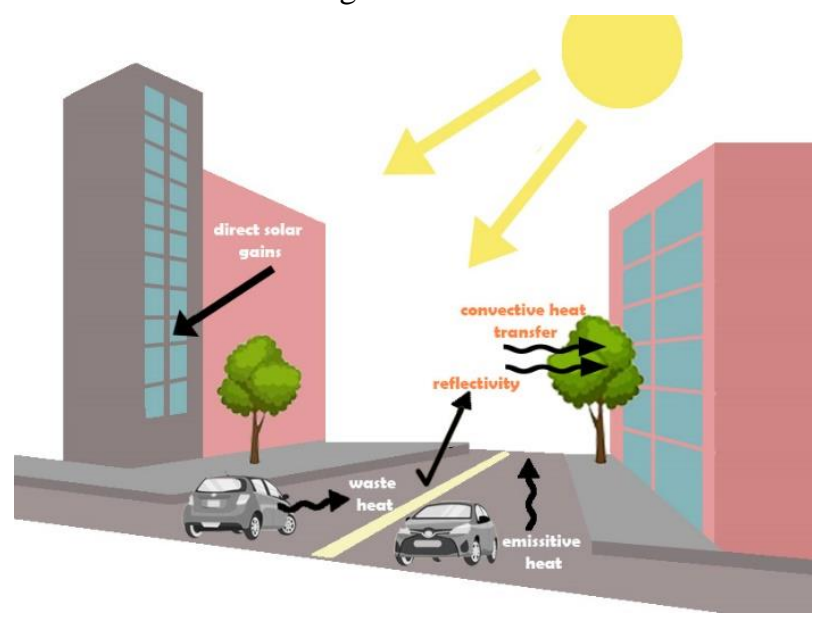

Figure 2: Main heat flows of an urban heat island.

In every heat flow of the urban heat island, various solutions have been proposed such as green surfaces and urban shading for the city surfaces, and street canyons for removing the accumulated heat.

Also, in all those cases, the immediate outdoor conditions of the buildings are affected thus the indoor thermal comfort can vary. Several authors have found that if the heat island effect increases the indoor air temperature and the relative humidity of the immediate buildings increase as well, producing a growth of energy consumption by using air-conditioning systems.

\section{Simplified mathematical model}

With the aforementioned heat flows onto the urban heat island, a simplified mathematical model is developed to calculate the outdoor temperature and the relative humidity after using the methods of shading, reflecting surfaces and ventilation proposed in literature.

Firstly, the temperature of the outdoor air, or temperature sol-air, is used as a boundary condition in the part 'outdoor temperature' in the EnergyPlus idf editor. This temperature is calculated as follows:

$$
T_{\text {sol-air }}=T_{o}+\frac{\alpha \cdot I_{C}-\Delta Q_{i r}}{h o}
$$

Where the incident irradiance and the additional infrared radiation are calculated as follows:

$$
\begin{gathered}
I_{c}=I_{G} \cdot \tau \\
\Delta Q_{\text {ir }}=F r \cdot h r \cdot \Delta T_{\text {outdoor }- \text { sky }}
\end{gathered}
$$

Thereby, the temperature sol-air is calculated based on the outdoor characteristics of irradiance, infrared radiation, convection \& radiation heat flow, and the optical characteristics of the place (transmittance, absorption). The solar irradiance, the infrared radiation and the outdoor temperature are estimated with WRF, while is other parameters are the factors to vary in order to counter the heat island effect.

Furthermore, the relative humidity is calculated as follows (Wanielista et al., 1997):

$$
\varphi=\frac{P v}{P v s} \cdot 100
$$

Where Pv and Pvs are estimated as the following:

$$
\begin{aligned}
& P v=6.112 \cdot \exp \left[\frac{17.7 \cdot T d}{T d+243.5}\right] \\
& P v s=6.11 \cdot \exp \left[\frac{17.27 \cdot T_{o}}{T_{o}+237.3}\right]
\end{aligned}
$$

From Eq. 4 to 6 it is seen that the relative humidity only depends on the calculated outdoor temperature and the dew point of the place. In this document, these parameters are estimated with the WRF model.

With Eq. 1 to 6 and with the mathematical program MatLab, the temperature sol-air and the relative humidity can be determined based upon five main variables: transmittance, absorption, global solar irradiance, additional infrared radiation and heat transfer coefficient by radiation $\&$ convection.

For three out of these five factors, one respective solution is hereby proposed as follows:

- For low absorption ( $\alpha$ ), green and/or reflective surfaces. 
- For low incident solar irradiance (I), low transmittance, shading vegetation and/or urban shading methods.

- For high coefficient of radiation \& convection heat transfer (ho), urban canyons and/or urban natural ventilation.

The additional infrared radiation due to the difference between the outdoor temperature and the temperature of the apparent sky is calculated with a form factor between the element and the sky, Fr, of 0.75 (considering that the layout of the surfaces of the urban area is half vertical and half horizontal). The external radiative heat transfer coefficient, hr, is set at $5.34 \mathrm{~W} / \mathrm{m}^{2} \mathrm{~K}$, in accordance to Evangelisti et al. (2017).

It is worthy to mention that in this document there is a distinction between 'vegetation' and 'green surfaces'. The first term comprises mainly trees that make a shade upon buildings, ground etc., whereas the second term refers to vegetation that do not make any kind of visible shade upon the urban area but decreases both the absorption and the emittance of the surfaces.

Thereby, the calculation method is presented in this document as hourly output data of the relative humidity and air temperature. Hence, these output data are set as input data in EnergyPlus calculating thus the indoor air temperature and indoor relative humidity, where the building is considered as single thermal zone.

\section{Outdoor conditions}

The first step of the calculation is getting the outdoor conditions from the WRF model, where the heat island effect is not considered, therefore these data can be seen as the first outdoor conditions of the calculation method. Mexico City is taken as case study due to its vulnerability for the heat island effect, finding a temperature difference between a rural and an urban area of $10^{\circ} \mathrm{C}$ in 2010 , including a temperature difference during nighttime (Matsumoto et al, 2014). Moreover, this city is considered because of the potential that it has to apply the proposed approaches presented here (vegetation, mainly). The WRF model can be seen in Figure 3.

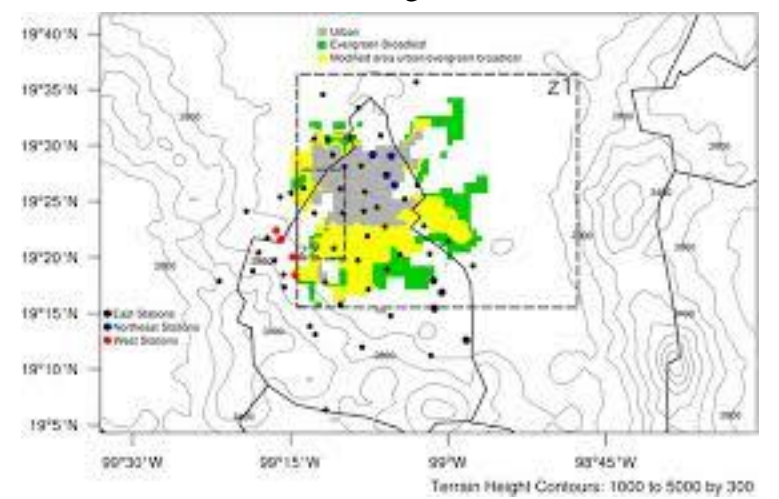

Figure 3: WRF modeling for Mexico City.

A typical hot-dry day is taken (May $18^{\text {th }}$ ). Table 1 shows the hourly values of outdoor temperature and global solar irradiance (taken from the WRF model) and the calculated sol-air temperature and relative humidity for this day. For estimating the hourly sol-air temperature and relative humidity, the hourly temperature of sky and dew point for Mexico City were also taken from the dynamic WRF model. Furthermore, the physical urban conditions are as follows: a general absorption of 0.7, a general transmittance of 0.9 and a convective \& radiation coefficient for urban areas of $45.7 \mathrm{~W} / \mathrm{m}^{2} \mathrm{~K}$ (Rosso et al., 2018). These physical characteristics are considered as regular for an urban area as Mexico City.

Table 1: Outdoor data from $W R F^{l}$ and the calculation method presented in this document ${ }^{2}$.

\begin{tabular}{|c|c|c|c|c|}
\hline Hour & $\begin{array}{c}\text { Outdoo } \\
\text { r air } \\
\text { temper } \\
\text { ature }^{1} \\
{[C]}\end{array}$ & $\begin{array}{c}\text { Global } \\
\text { solar } \\
\text { irradia } \\
\text { nce }^{1} \\
{\left[\mathrm{~W} / \mathrm{m}^{2}\right]}\end{array}$ & $\begin{array}{c}\text { Temp } \\
\text { eratur } \\
\text { e sol- } \\
\text { air } \\
{[C]}\end{array}$ & $\begin{array}{c}\text { Relative } \\
\text { humidit } \\
\mathbf{y}^{2}[\%]\end{array}$ \\
\hline 1 & 17.42 & 0.00 & 16.44 & 55.12 \\
\hline 2 & 16.42 & 0.00 & 15.44 & 57.12 \\
\hline 3 & 16.00 & 0.00 & 15.03 & 58.64 \\
\hline 4 & 16.00 & 0.00 & 15.03 & 58.64 \\
\hline 5 & 15.42 & 0.00 & 14.47 & 65.83 \\
\hline 6 & 14.42 & 0.00 & 13.46 & 68.73 \\
\hline 7 & 12.83 & 26.78 & 12.28 & 73.00 \\
\hline 8 & 13.75 & 111.15 & 14.47 & 65.09 \\
\hline 9 & 16.75 & 217.73 & 19.07 & 48.61 \\
\hline 10 & 19.75 & 312.83 & 23.50 & 37.06 \\
\hline 11 & 22.17 & 474.00 & 28.34 & 27.82 \\
\hline 12 & 23.58 & 558.82 & 31.02 & 22.91 \\
\hline 13 & 24.29 & 740.18 & 34.45 & 18.14 \\
\hline 14 & 24.79 & 712.80 & 34.52 & 17.43 \\
\hline 15 & 25.58 & 639.08 & 34.19 & 17.39 \\
\hline 16 & 24.83 & 550.05 & 32.12 & 20.33 \\
\hline 17 & 25.17 & 401.03 & 35.17 & 15.64 \\
\hline 18 & 25.42 & 224.48 & 32.74 & 17.09 \\
\hline 19 & 23.25 & 42.15 & 27.87 & 25.21 \\
\hline 20 & 21.42 & 0.00 & 25.43 & 30.84 \\
\hline 21 & 18.67 & 0.00 & 22.72 & 40.87 \\
\hline 22 & 16.42 & 0.00 & 18.51 & 59.91 \\
\hline 23 & 16.58 & 0.00 & 17.66 & 60.09 \\
\hline 24 & 15.25 & 0.00 & 15.32 & 65.95 \\
\hline
\end{tabular}

Results in Table 1 show a maximum difference of $10.2 \mathrm{~K}$ between the outdoor air temperature and the outdoor air temperature considering the heat island effect. This maximum difference is found at 13:00 h, when the highest solar irradiance is registered. Furthermore, the lowest relative humidity is found at 17:00 h, and the highest is found at 7:00 h.

\section{Validation of the results}

Regarding the validation of the results, when these are compared to data presented by Jauregui (1997), Ballinas et al.(2012) and Barradas et al. (1999) for Mexico City, it is noticed that the maximum temperature difference for the four documents, both for daytime and nighttime, is on the same order of magnitude as it is shown in Table 2. It is important to state that the parameters used in this document are based on the physical parameter of the 
urban layout (transmittance, absorption and convective coefficient). In the three mentioned studies, the estimations were carried out with other parameters proper of the meteorological stations such as relative humidity and diffuse radiation. Nevertheless, taking account of the simplicity of the model, the results are considered as valid and useful for estimating the influence of the solutions for countering the heat island effect.

Table 2: Comparison of maximum difference of temperature with and without heat island of four studies.

\begin{tabular}{|l|l|l|}
\hline Document & $\begin{array}{l}\text { Maximum } \\
\text { temperature } \\
\text { difference- } \\
\text { daytime [K] }\end{array}$ & $\begin{array}{l}\text { Maximum } \\
\text { temperature } \\
\text { difference - } \\
\text { nighttime [K] }\end{array}$ \\
\hline Jauregui & 8.7 & 7.8 \\
\hline Ballinas et al. & 10.0 & 6.0 \\
\hline Barradas et al. & 10.5 & N/A \\
\hline This paper & 10.2 & 7.3 \\
\hline
\end{tabular}

\section{Indoor conditions}

Using an already-published simulation model of a single dwelling located in Mexico City and with its proper characteristics of construction and occupant behavior, simulations by using EnergyPlus are run to estimate the hourly indoor air temperature and indoor relative humidity, mainly. In EnergyPlus the function SizingPeriod:DesignDay is used with the data of sol-air temperature and relative humidity as input. Table 3 shows the results of the simulation along with the PMV index considering a wind speed of $1 \mathrm{~m} / \mathrm{s}$, clothing of 1 clo and a metabolic rate of 1 met.

In addition, a cooling demand is hourly calculated based on an indoor temperature of comfort of $25 \mathrm{C}$ and with the already-published calculator of cooling demand developed by Oropeza-Perez (2017), contemplating an average single dwelling of $100 \mathrm{~m}^{2}$ of built area and $2.5 \mathrm{~m}$ of ceiling height with typical conditions of construction and occupancy (Oropeza-Perez et al., 2012). These characteristics of construction and occupancy are the same than the used for calculating the hourly indoor temperature and the hourly PMV index.

Table 3: Indoor data from thermal simulations by using EnergyPlus.

\begin{tabular}{|r|r|r|r|r|}
\hline Hour & $\begin{array}{c}\text { Indoo } \\
\text { r air } \\
\text { tempe } \\
\text { rature } \\
\text { [C] }\end{array}$ & $\begin{array}{c}\text { Relative } \\
\text { humidit } \\
\mathbf{y}[\%]\end{array}$ & $\begin{array}{c}\text { PMV } \\
\text { Index }\end{array}$ & $\begin{array}{c}\text { Cooling } \\
\text { demand } \\
\text { (kWh) }\end{array}$ \\
\hline 1 & 30.00 & 24.29 & 1.33 & 0.42 \\
\hline 2 & 29.82 & 23.86 & 1.27 & 0.41 \\
\hline 3 & 29.62 & 24.14 & 1.20 & 0.39 \\
\hline 4 & 29.39 & 24.46 & 1.13 & 0.37 \\
\hline 5 & 29.17 & 26.81 & 1.08 & 0.35 \\
\hline 6 & 29.06 & 26.38 & 1.04 & 0.34 \\
\hline 7 & 28.88 & 26.21 & 0.98 & 0.33 \\
\hline 8 & 28.71 & 27.24 & 0.93 & 0.31 \\
\hline 9 & 28.70 & 27.25 & 0.93 & 0.31 \\
\hline
\end{tabular}

\begin{tabular}{|l|l|l|l|l|}
\hline 10 & 28.67 & 27.30 & 0.92 & 0.31 \\
\hline 11 & 28.65 & 27.33 & 0.91 & 0.31 \\
\hline 12 & 28.68 & 26.21 & 0.91 & 0.31 \\
\hline 13 & 28.80 & 24.99 & 0.94 & 0.32 \\
\hline 14 & 28.97 & 23.86 & 0.98 & 0.33 \\
\hline 15 & 29.18 & 23.11 & 1.04 & 0.35 \\
\hline 16 & 29.41 & 23.73 & 1.13 & 0.37 \\
\hline 17 & 29.61 & 21.40 & 1.17 & 0.39 \\
\hline 18 & 29.85 & 20.14 & 1.23 & 0.41 \\
\hline 19 & 30.07 & 22.20 & 1.33 & 0.43 \\
\hline 20 & 30.23 & 23.30 & 1.40 & 0.44 \\
\hline 21 & 30.29 & 26.17 & 1.45 & 0.45 \\
\hline 22 & 30.33 & 29.53 & 1.50 & 0.45 \\
\hline 23 & 30.29 & 28.15 & 1.47 & 0.45 \\
\hline 24 & 30.19 & 26.77 & 1.42 & 0.44 \\
\hline
\end{tabular}

In Table 3 one can see that during this day of May $18^{\text {th }}$, out of the 24 hours, 24 are considered as slight warm conditions for Mexico (Oropeza-Perez et al., 2017). Thereby, $100 \%$ of the time presents thermal discomfort. Furthermore, this is reflected in an aggregated cooling demand of $8.99 \mathrm{kWh}$ for the same day.

\section{Results}

In order to counter the effects of urban island upon the buildings, two different approaches are proposed. Both proposals are in concordance of the solutions given by different authors. The first one consists in placing reflective materials in the street as well as in the building surfaces. These reflective materials can be porous materials, green surfaces, or low- absorption materials. Therefore, if the general absorption is decrease at 0.35 considering a with-painted building and green surfaces at its surroundings (Hirano and Fujita, 2016), Table 4 can be displayed.

Table 4: Indoor data from the calculation method presented in this document.

\begin{tabular}{|r|c|c|c|c|}
\hline Hour & $\begin{array}{c}\text { Indoor } \\
\text { air } \\
\text { temper } \\
\text { ature } \\
{[\mathbf{C}]}\end{array}$ & $\begin{array}{c}\text { Relati } \\
\text { ve } \\
\text { humi } \\
\text { dity } \\
{[\%]}\end{array}$ & $\begin{array}{c}\text { PMV } \\
\text { Index }\end{array}$ & $\begin{array}{c}\text { Cooling } \\
\text { demand } \\
\text { (kWh) }\end{array}$ \\
\hline 1 & 25.95 & 30.75 & 0.04 & 0.08 \\
\hline 2 & 25.82 & 30.13 & -0.01 & 0.07 \\
\hline 3 & 25.69 & 30.36 & -0.05 & 0.06 \\
\hline 4 & 25.54 & 30.63 & -0.10 & 0.05 \\
\hline 5 & 25.45 & 33.34 & -0.10 & 0.04 \\
\hline 6 & 25.56 & 32.38 & -0.08 & 0.05 \\
\hline 7 & 25.50 & 31.95 & -0.10 & 0.04 \\
\hline 8 & 25.42 & 33.03 & -0.12 & 0.04 \\
\hline 9 & 25.53 & 32.82 & -0.08 & 0.04 \\
\hline 10 & 25.54 & 32.80 & -0.08 & 0.05 \\
\hline 11 & 25.57 & 32.74 & -0.07 & 0.05 \\
\hline 12 & 25.62 & 31.35 & -0.06 & 0.05 \\
\hline 13 & 25.69 & 29.99 & -0.05 & 0.06 \\
\hline
\end{tabular}




\begin{tabular}{|r|r|r|r|r|}
\hline 14 & 25.79 & 28.74 & -0.03 & 0.07 \\
\hline 15 & 25.91 & 27.97 & 0.00 & 0.08 \\
\hline 16 & 26.03 & 28.91 & 0.05 & 0.09 \\
\hline 17 & 26.04 & 26.35 & 0.03 & 0.09 \\
\hline 18 & 26.11 & 25.04 & 0.04 & 0.09 \\
\hline 19 & 26.24 & 27.73 & 0.11 & 0.10 \\
\hline 20 & 26.32 & 29.25 & 0.15 & 0.11 \\
\hline 21 & 26.31 & 32.98 & 0.18 & 0.11 \\
\hline 22 & 26.32 & 37.27 & 0.22 & 0.11 \\
\hline 23 & 26.25 & 35.59 & 0.18 & 0.11 \\
\hline 24 & 26.16 & 33.84 & 0.14 & 0.10 \\
\hline
\end{tabular}

From Table 4 one can see that the PMV index never overpasses 0.25 , which is considered as conditions of thermal comfort. This is explained because there is an average indoor temperature drop of $3.6 \mathrm{~K}$. Moreover, the daily consumption is estimated at $1.72 \mathrm{kWh}$.

As a second approach, it is stated the placement of shading vegetation to filter the solar irradiance. With this is expected to decrease the value of solar transmittance onto the modeled building. If the general transmittance is decrease at 0.40, as it is found by Oshio and Asawa (2016) with zelkova serrata trees, results are shown in Table 5.

Table 5: Indoor data from the calculation method presented in this document.

\begin{tabular}{|c|c|c|c|c|}
\hline Hour & $\begin{array}{c}\text { Indoor } \\
\text { air } \\
\text { temper } \\
\text { ature } \\
{[C]}\end{array}$ & $\begin{array}{c}\text { Relative } \\
\text { humidit } \\
\mathbf{y}[\%]\end{array}$ & $\begin{array}{l}\text { PMV } \\
\text { Index }\end{array}$ & $\begin{array}{r}\text { Cooling } \\
\text { demand } \\
(\mathbf{k W h})\end{array}$ \\
\hline 1 & 28.51 & 26.47 & 0.86 & 0.30 \\
\hline 2 & 28.33 & 26.00 & 0.79 & 0.28 \\
\hline 3 & 28.14 & 26.29 & 0.73 & 0.26 \\
\hline 4 & 27.92 & 26.63 & 0.66 & 0.25 \\
\hline 5 & 27.77 & 29.08 & 0.63 & 0.23 \\
\hline 6 & 27.81 & 28.37 & 0.64 & 0.24 \\
\hline 7 & 27.65 & 28.15 & 0.58 & 0.22 \\
\hline 8 & 27.47 & 29.28 & 0.54 & 0.21 \\
\hline 9 & 27.45 & 29.31 & 0.53 & 0.21 \\
\hline 10 & 27.41 & 29.38 & 0.52 & 0.20 \\
\hline 11 & 27.41 & 29.38 & 0.52 & 0.20 \\
\hline 12 & 27.47 & 28.12 & 0.52 & 0.21 \\
\hline 13 & 27.56 & 26.86 & 0.54 & 0.22 \\
\hline 14 & 27.72 & 25.66 & 0.58 & 0.23 \\
\hline 15 & 27.92 & 24.86 & 0.64 & 0.25 \\
\hline 16 & 28.13 & 25.56 & 0.72 & 0.26 \\
\hline 17 & 28.25 & 23.15 & 0.73 & 0.27 \\
\hline 18 & 28.38 & 21.92 & 0.77 & 0.29 \\
\hline 19 & 28.62 & 24.13 & 0.87 & 0.31 \\
\hline 20 & 28.79 & 25.32 & 0.94 & 0.32 \\
\hline 21 & 28.85 & 28.43 & 0.99 & 0.32 \\
\hline 22 & 28.89 & 32.08 & 1.04 & 0.33 \\
\hline 23 & 28.82 & 30.63 & 1.00 & 0.32 \\
\hline 24 & 28.72 & 29.13 & 0.95 & 0.24 \\
\hline
\end{tabular}

Table 5 shows that in this case, out of the 24 hours, 7 present a slight warm sensation (PMV higher than 0.8), whereas at least 12 hours are very close to reach this status. With this approach the average temperature drop is only $1.4 \mathrm{~K}, 2.2 \mathrm{~K}$ less than the achieved by reflective surfaces. For this case the daily cooling demand is estimated at $4.40 \mathrm{kWh}$.

When both approaches are considered together (absorption of 0.35 and transmittance 0.4 upon the urban area), the simplified model calculates the results shown in Table 6.

Table 6: Indoor data from the calculation method presented in this document.

\begin{tabular}{|c|c|c|c|c|}
\hline Hour & $\begin{array}{c}\text { Indoor } \\
\text { air } \\
\text { temperat } \\
\text { ure [C] }\end{array}$ & $\begin{array}{c}\text { Relative } \\
\text { humidit } \\
\mathbf{y}[\%]\end{array}$ & $\begin{array}{l}\text { PMV } \\
\text { Index }\end{array}$ & $\begin{array}{c}\text { Cooling } \\
\text { demand } \\
(\mathbf{k W h})\end{array}$ \\
\hline 1 & 25.12 & 32.30 & -0.22 & 0.01 \\
\hline 2 & 25.00 & 31.63 & -0.27 & 0.00 \\
\hline 3 & 24.89 & 31.84 & -0.30 & -0.01 \\
\hline 4 & 24.77 & 32.07 & -0.34 & -0.02 \\
\hline 5 & 24.73 & 34.80 & -0.33 & -0.02 \\
\hline 6 & 24.87 & 33.74 & -0.29 & -0.01 \\
\hline 7 & 24.82 & 33.27 & -0.32 & -0.02 \\
\hline 8 & 24.75 & 34.38 & -0.33 & -0.02 \\
\hline 9 & 24.84 & 34.19 & -0.30 & -0.01 \\
\hline 10 & 24.87 & 34.13 & -0.29 & -0.01 \\
\hline 11 & 24.89 & 34.09 & -0.29 & -0.01 \\
\hline 12 & 24.94 & 32.65 & -0.28 & -0.01 \\
\hline 13 & 24.99 & 31.26 & -0.28 & 0.00 \\
\hline 14 & 25.08 & 29.98 & -0.26 & 0.01 \\
\hline 15 & 25.17 & 29.22 & -0.23 & 0.01 \\
\hline 16 & 25.28 & 30.22 & -0.19 & 0.02 \\
\hline 17 & 25.25 & 27.61 & -0.22 & 0.02 \\
\hline 18 & 25.26 & 26.33 & -0.23 & 0.02 \\
\hline 19 & 25.40 & 29.15 & -0.16 & 0.03 \\
\hline 20 & 25.50 & 30.70 & -0.11 & 0.04 \\
\hline 21 & 25.48 & 34.64 & -0.08 & 0.04 \\
\hline 22 & 25.49 & 39.15 & -0.04 & 0.04 \\
\hline 23 & 25.42 & 37.39 & -0.08 & 0.04 \\
\hline 24 & 25.32 & 35.56 & -0.13 & 0.03 \\
\hline
\end{tabular}

When the approaches of reducing both the urban absorption and transmittance are combined, an average indoor temperature decrease of $4.4 \mathrm{~K}$ is calculated. Also, a cooling demand for this day is estimated at $0.18 \mathrm{kWh}$. In this case the 24 hours are considered under thermal comfort.

From Tables 4 to 6 it is clearly seen that reflective materials have a more influence upon the indoor air temperature. This can be explained with the fact that the surfaces covered by reflected materials are not only placed at the urban area, but also in the building envelope, where the roof is an important element. On the other hand, 
the transmittance drop only has an influence upon the windows and other transparent surfaces.

Furthermore, if a sensitive analysis is carried out, Figure 4 can be displayed. The cooling demand is estimated for Mexico City at May $18^{\text {th }}$ upon the modeled building used for the prior cases. When the value of the thermal absorption is varied, a transmittance of 0.9 is considered. When the value of thermal transmittance changes, an absorption of 0.7 is set up. In Figure 4 the value of the cooling demand for the modeled building is calculated.

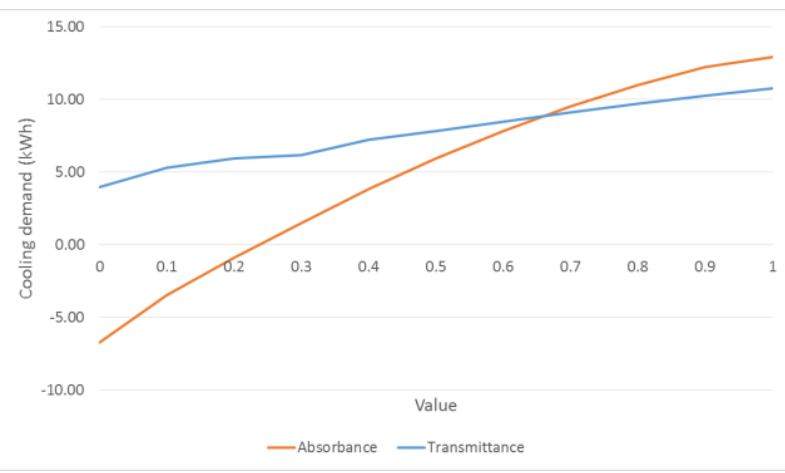

Figure 4: Sensitivty analysis of cooling demand varying thermal absorption and thermal transmittance.

In accordance with the results shown in Tables 4 to 6 , the thermal absorption has a higher influence than the thermal transmittance onto the indoor thermal comfort of the modeled building. Moreover, an absorption lower than 0.25 could entail an overcooling.

\section{Conclusion}

A simplified mathematical model along with WRF model and EnergyPlus is used to calculate the thermal comfort and cooling demand within a building taking account of the heat island effect.

Using a WRF model, the hourly temperature of the outdoor air and the hourly dew point is calculated for a certain city. With the mathematical model developed here, a second outdoor air temperature is calculated considering the physical parameters proper of an urban area (absorption, transmittance, convective heat). This new outdoor temperature is set as input in EnergyPlus where the hourly indoor temperature, relative humidity and PMV index of a building is calculated.

Thereby, it is found that the effect of thermal absorption of the materials placed both at the urban layout and the buildings has more influence than the effect of thermal transmittance presented here as trees. Nonetheless, a combination of both approaches reduces even more the effect of heat island being reflected at thermal comfort and almost zero cooling demand for this day in specific, and with a considerable energy demand reduction if all year is considered.

Therefore, it is highly recommended the placement of reflective materials in the streets and the buildings as well as leafy trees and other vegetation that will help to achieve indoor thermal comfort while saving energy for not using air-conditioning systems.
It is important to mention that the use of urban canyons and other urban ventilation was not addressed in this document. This approach is important because it would increase the convection $\&$ radiation coefficient that it is reflected on the removing of the waste heat generated by energy activities such as factories and cars, and which is the second cause of the heat island effect.

As a final comment, it is important to stablish the limitations of the mathematical model, which only depends on the physical parameters of absorption, transmittance and convective heat transfer. Other parameters such as the dynamic changes on the human behavior and climate characteristics should be considered in order to achieve a more accurate model for analyzing the heat island onto an urban context.

\section{Acknowledgement}

The author wants to thank Dr. Astrid H. PetzoldRodriguez for the useful feedback talks.

\section{Nomenclature}

$\alpha=$ Thermal absorption [dimensionless]

$\varphi=$ Relative humidity [\%]

$\tau=$ Thermal transmittance [dimensionless]

$\Delta \mathrm{Q}_{\text {ir }}=$ Additional infrared radiation due to the difference between the outdoor temperature and the temperature of the apparent sky $\left[\mathrm{W} / \mathrm{m}^{2}\right]$

$\Delta \mathrm{T}_{\text {outdoor-sky }}=$ Difference between outside dry-bulb air temperature and sky mean radiant temperature [K]

$F_{r}=$ Form factor between the element and the sky [dimensionless]

$\mathrm{H}_{\mathrm{o}}=$ Coefficient of heat transfer by radiation and convection $\left[\mathrm{W} / \mathrm{m}^{2} \mathrm{~K}\right]$

$\mathrm{H}_{\mathrm{r}}=$ External radiative heat transfer coefficient $\left[\mathrm{W} / \mathrm{m}^{2} \mathrm{~K}\right]$

$\mathrm{I}_{\mathrm{C}}=$ Incident solar irradiance $\left[\mathrm{W} / \mathrm{m}^{2}\right]$

$\mathrm{I}_{\mathrm{G}}=$ Global solar irradiance $\left[\mathrm{W} / \mathrm{m}^{2}\right]$

$\mathrm{Pv}=$ Actual vapor density $\left[\mathrm{g} / \mathrm{m}^{3}\right]$

$\mathrm{PVs}=$ Saturation vapor density $\left[\mathrm{g} / \mathrm{m}^{3}\right]$

$\mathrm{T}_{\mathrm{d}}=$ Dew point $[\mathrm{C}]$

$\mathrm{T}_{\mathrm{o}}=$ Outdoor air temperature $[\mathrm{C}]$

$\mathrm{T}_{\text {sol-air }}=$ Temperature sol-air $[\mathrm{C}]$

\section{References}

Allegrini J., Carmeliet J. (2018) Simulations of local heat islands in Zürich with coupled CFD and building energy models. Urban Climate 24, 340-359.

Ballinas, M., \& Barradas, V. (2012) The actual urban heat island in Mexico City. $8^{\text {th }}$ International Conference on Urban Climate. Dublin (UK), 173-183 August 2012.

Barradas, V.L., Tejeda-Martinez, A., Jauregui, E. (1999) Energy balance measurements in a suburban vegetated area in Mexico City. International Conference on Urban Climatology. Essen (Germany) 4109-4113.

Chen, F., Yang, X., Zhu, W. (2014) WRF simulations of urban heat island under hot-weather synoptic 
conditions: The case study of Hangzhou City, China. Atmospheric Research 138, 364-377.

Evangelisti, L., Guattari, C., Gori P., Bianchi, F. (2017) Heat transfer study of external convective and radiative coefficients for building applications. Energy and Buildings 151, 429-438.

Giannaros, C., Nenes, A., Giannaros, T.M., Kourtidis, K. (2018) A comprehensive approach for the simulation of the Urban Heat Island Effect with the WRF/SLUCM modeling system: The case of Athens (Greece). Atmospheric Research 201, 86-101.

Hirano, Y., Fujita, T. Simulating the $\mathrm{CO} 2$ reduction caused by decreasing the airconditioning load in an urban area. (2016) Energy and Buildings 114, 87-95.

Jandaghian, Z., Touchaei, A.G., Akbari, H. (2018) Sensitivity analysis of physical parameterizations in WRF for urban climate simulations and heat island mitigation in Montreal. Urban Climate 24, 577-599.

Jauregui, E. (1997) Heat island development in Mexico City. Atmospheric Environment 31, 3821-3831.

Li, H., Zhou, Y., Wang, X., Zhou, X., Zhang, H., Sodoudi, S. (2019) Quantifying urban heat island intensity and its physical mechanism using WRF/UCM. Science of the Total Environment 650, 3110-3119.

Li, X., Zhou, Y., Yu, S., Jia, G., Li, H., Li, W. (2019) Urban heat island impacts on building energy consumption: A review of approaches and findings. Energy 174, 407-419.

Matsumoto, Y., Valdes, M., Urbano, J.A., Kobayashi, T., Lopez, G., Peña, R. (2014) Global solar irradiation in north Mexico City and some comparisons with the south. Energy Procedia 57, 1179-1188.

Mirzae, P.A. Recent challenges in modeling of urban heat island. Sustainable Cities and Society 19, 200-206.

Morini, E., Touchaei, A.G., Rossi, F., Cotana, F., Akbari, H. ((2018) Evaluation of albedo enhancement to mitigate impacts of urban heat island in Rome (Italy) using WRF meteorological model. Urban Climate 24, $551-566$
Oropeza-Perez, I., Ostergaard, P.A., Remmen, A. (2012) Model of natural ventilation by using a coupled thermal-airflow simulation program. Energy and Buildings 49, 388-393.

Oropeza-Perez, I. (2017) Development of a cooling-load calculator for the Mexican conditions of climate, construction and occupancy. Procedia Engineering 205, 1115-1122.

Oropeza-Perez, I., Petzold-Rodriguez, A.H., BonillaLopez, C. (2017) Adaptive thermal comfort in the main Mexican climate conditions with and without passive cooling. Energy and Buildings 145, 251-258.

Oshio, H., Asawa, T. (2016) Estimating the solar transmittance of urban trees using airborne LiDAR and radiative transfer simulation. IEEE Transactions on Geoscience and Remote Sensing 54, 5483-5492.

Rosso, F., Golasi, I., Castaldo, V.L., Piselli, C., Pisello, A.L., Salata F., Ferrero, M., Cotana, F., Vollaro, A.L. (2018) On the impact of innovative materials on outdoor thermal comfort of pedestrians in historical urban canyons. Renewable Energy 118, 825-839.

U. S. Department of Energy. Energy Plus software (2019).

Mesoscale and Microscale Meteorology Laboratory. U. S. National Center for Atmospheric Research. The Weather Research and Forecasting Model (2019).

Wanielista, M., Kersten, R., Eaglin, R. (1997) Hydrology Water Quantity and Quality Control. John Wiley \& Sons. London (UK).

Yang, X., Yao. L., Peng, L.L.H., Jiang, Z., Jin, T., Zhao, L. (2019) Evaluation of a diagnostic equation for the daily maximum urban heat island intensity and its application to building energy simulations. Energy and Buildings 193, 160-173.

Yuan, J., Emura, K., Farnham, C., Sakai, H. (2016) Application of glass beads as retro-reflective facades for urban heat island mitigation: Experimental investigation and simulation analysis. Building and Environment 105, 140-152. 